\title{
Distribution of sulfa resistant bacteria and resistance gene of $E$. coli in different poultry farm regions
}

\author{
Minglan Jin ${ }^{1,2 a}$, Yuxin Zhao ${ }^{1}$, Shimei Sun ${ }^{1}$, Yingying $X u^{1}$, Honghai $X u e^{1}$, \\ Xiaoyu Zhang ${ }^{1}$, Ying Wang ${ }^{1}$, Yingzi Lin ${ }^{1 b}$, Ningyi Jin ${ }^{2}$ \\ ${ }^{1}$ Key Laboratory of Songliao Aquatic Environment, Ministry of Education, Jilin Architectural \\ University, Changchun 130118, China; \\ ${ }^{2}$ Institute of Military Veterinary Medicine, Academy of MilitaryMedical Sciences, Changchun 130122, \\ China \\ aemail: jinminglan68@126.com, bemail: linyingzi1000@126.com.cn
}

Key words: Antibiotics; Sulfanilamide sensitivity;Multiple antibiotic resistance; Resistance genes; Poultry farms

\begin{abstract}
Antibiotic resistance had increased in recent years, raising the concern of public health authorities. 210 Escherichia coli (E. coli) were isolated from soil samples around the chicken farm, dove farm and quails farm to assess the prevalence of antimicrobial resistance. Broth microdilution and PCR were used for the sulfonamides susceptibility testing and detection of sulphonamides resistance genes respectively. Between the isolates, 66 (31.4\%) were susceptible to sulfamethoxazole agents. The separated sulfonamides -resistant also exhibit resistance to other of antibiotics according to CLSI standard. And so sulfonamides -resistant bacteria had the highest resistance to chloramphenicol, middle resistance to tolerance ability of penicillin, tetracycline, ciprofloxacin and the lowest resistance to rifamicin. Sulfonamide resistance was different from isolated E. coli. sul1, sul 2 and int 1 were detected more higher than int 2 and sul 3. In addition, there were 89 detected resistance genes in soil. Among them, there were 48 strains contained one kind of resistance genes. Meantime, there were 6 strains contained two kinds of resistance genes, while there were 4 strains contained three kinds of resistance genes. Only there was 1 strain contained four genes in the chicken farm, dove farm and quails farm, respectively. So was1 strain contained five genes in the chicken farm. Oddly enough, 4 sensitivity strains were not detected resistance gene. The results showed that the sulfonamide resistance of bacteria had multiple antibiotic resistances which were isolated from $E$. coli in the poultry farm. While different proportion of sulfonamides resistance genes was observed in different animal species. In conclusion, antibiotic resistance bacteria and resistance genes related with a lot of factors, mutations in genes involved in drug metabolism have been well-associated with drug resistance. Obviously, the sulfonamides resistance did not coincide with the presence of such genes completely in this study.
\end{abstract}

\section{Introduction}

Across the globe, lots kinds of antimicrobial agents were available for therapy and prophylaxis of infectious diseases, or as growth promotion in animals, and protect humans. However, during the last decades, the mishandling and misprescription of antibiotics in human and veterinary medicine, as well as their use as growth promoters in animal husbandry, resulted in the increase in the prevalence of bacteria resistant to multiple antibiotics, while the bacterial strains of farms had become a reservoir for antibiotic-resistant bacteria, had created a selective pressure leading to the emergence and spread of bacterial strains that no longer respond to antimicrobial therapy [1]. Antibiotic resistant bacteria had been largely found in soil and water, as a result of environmental contamination during processing, while the bacterial strains of farms had become a reservoir for antibiotic-resistant bacteria. Antibiotic resistance has being a growing and worrying problem associated with increased deaths and suffering for people, impact on agriculture, environmental security, which was a common worldwide problem attention. Whereas, only a few systematic studies were reported on the development of resistance bacteria in soil, water around farm and its 
relationship with antibiotics in feed [2]. A new type of environmental pollutants with the transfer of antibiotic resistance genes could have more adverse effects on the environment than the antibiotic resistance genes themselves, while the horizontal gene transfer could be the most important propagation pathways of the antibiotic resistance genes, being one of the reasons for more and more growing pollution of antibiotic resistance genes in the environment [3].Until now, most studies on resistant non-pathogenic species have focused mainly on E.coli. A limited information on the antimicrobial susceptibility profiles of E.coli was available, as well as their possible involvement in the dispersal of antimicrobial resistance determinants between bacteria. E.coli was an important pathogen in poultry, medicine and public health. Sulfa drugs were a kind of cheap, broad spectrum, synthesis of antibacterial drugs, for the majority of gram-positive and gram-negative bacteria are effective, had been widely used in the prevention and treatment of various infectious diseases, which cause a variety of drug hypersensitivity-based idiosyncratic antibiotic resistance genes, which was attributed to sulfa drugs reactive metabolites [4]. Consequently, including sulfa drugs had become crucial in understanding the mechanisms responsible for these antibiotic resistance genes. In addition, sulfa drugs were used widely, the sensitivity of bacteria was week, causing antibiotic resistance genes to be focus on.

Because many kinds of antibiotics were used at the chickens farm, quail farm and pigeon farm, this study therefore aimed at characterizing E.coli isolated from soil samples from poultry farms in the JiLin Province of Northeast China. Application routine bacteria separation method for separation and identification of different poultry farm, 210 E.coli in different area, with trace dilution method and PCR to detect sulfa antibiotics resistance, the distribution of resistance genes, analysis of antibiotic resistance, antibiotic resistant bacteria and the correlation of antibiotic resistance genes, reveal the resistant bacteria and resistance genes in different farms, farm area distribution, to effectively control the dangers of antibiotics and resistance bacteria.

\section{Methods}

\section{Bacteria isolation and identification}

Samples were transported to the laboratory in cool conditions and processed within two hours of collection. Farm field, 100 m, 200 m,500 m, 1000 m, $2000 \mathrm{~m}$ and $5000 \mathrm{~m}$ within the scope of the soil for the sampling points, 10 samples were collected at each sampling site around the chicken farm, dove farm and quails farm, a total of 210 samples. Soil (10-20 cm below the surface) was collected after a refrigerator sterilely. Approximately $1 \mathrm{~g}$ of each sample was mixed in $9 \mathrm{ml}$ of Trypticase soya broth with $20 \mathrm{mg} / \mathrm{L}$ novobiocine. A $10 \mathrm{~mL}$ aliquot soil of serial ten-fold dilutions for each sample was filtered through a $0.22 \mu \mathrm{m}$ pore membrane which was then placed on plate count agar and incubated aerobically at $37^{\circ} \mathrm{C}$ for $24-48$ hours. Isolates the conventional methods, application, glucose, lactose, maltose, sweet sugar, sugar fermentation tests, citrate salt test, methyl $\mathrm{red} / \mathrm{VP}$ and indole test methods of identification.

\section{Antibiotic resistance testing}

Once the bacteria was isolated and identified from each sample collected, the standard Kirby-Bauer disk diffusion method was used to determine the antimicrobial susceptibility profiles of the isolates [5]. Bacterial was prepared by suspending the freshly grown bacteria in 4-5 ml sterile nutrient broth and the turbidity was adjusted to that of a 0.5 McFarland standard. The antimicrobial susceptibility testing was performed using Mueller-Hinton medium against ampicillin, tetracycline, ciprofloxacin, chloramphenicol, gentamicin and rifampicin, which were used in the farms. Results obtained were used to classify isolates as being resistant or susceptible to a particular antibiotic using standard reference values. The plates were incubated concentration gradient of $2^{1}-2^{10} \mathrm{mg} \bullet \mathrm{L}^{-1}$ in the nutrient medium aerobically at $37^{\circ} \mathrm{C}$ for $18-24$ hours. The zones of inhibition were measured and compared with National Committee for Clinical Laboratory Standards (NCCLS) guidelines in drug sensitive test standard defines the highest concentration of 6 kinds of antibiotic resistance, all testing design parallel repeat 3 times [6]. Results obtained were used to susceptible to a particular antibiotic using standard reference values. 


\section{PCR to detect resistance gene}

Template DNA was prepared as previously described by Zhang [7], then according to the DNA kit to extract the DNA in the samples, which collected in a DNase free Eppendorf tube and stored at $-20{ }^{\circ} \mathrm{C}$. These were then used as templates in all the polymerase chain reactions that were performed in this study. The genes responsible for sulfa antibiotics resistance to sul1, sul2, sul3, int 1 and int2 were detected respectively using specific primers as described previously [8-9]. PCR products were separated by $120-\mathrm{V}$ electrophoresis in a $2 \%$ agarose gel containing ethidium bromide for $45 \mathrm{~min}$, visualized in Alliance 4.7 transilluminator and photographed.

\section{Statistical analysis}

Data was entered in to SPSS version 16 computer program. P-values less than 0.05 were taken as statistically significant.

\section{Test results}

\section{E. coli sulfa antibiotics resistance}

210 strains were isolated from poultry farms, 66 strains were detected to resistance for sulfa antibiotics resistance test, separate rate of the total was $31.4 \%$. 28, 21and17 were detected at chicken farm, quail farm and pigeon farm, respectively. 9,6,4,3,4,1and 2 were detected from the chicken farm field, 100 m, 200 m, 500 m, 1000 m, 2000 m, 5000m, respectively. 7,4,3,2,3,1 and1 were detected from the quail farm field, $100 \mathrm{~m}, 200 \mathrm{~m}, 500 \mathrm{~m}, 1000 \mathrm{~m}, 2000 \mathrm{~m}, 5000 \mathrm{~m}$, respectively. Meantime, 7,4,3,2,0,1and 0 were detected from pigeon farm field, $100 \mathrm{~m}, 200 \mathrm{~m}, 500$ $\mathrm{m}, 1000 \mathrm{~m}, 2000 \mathrm{~m}, 5000 \mathrm{~m}$, respectively. There were 3 resistant bacteria from $5000 \mathrm{~m}$ around farms, accounting for $4.5 \%$ of the sulfa resistant bacteria, and then there were 23 resistant bacteria within farm field, accounted for $38.4 \%$ of sulfa resistant bacteria. The results showed in table 1 . Interesting, the number of resistant bacteria in 1000 meters from farms were higher than in $500 \mathrm{~m}$, and then the number of resistant bacteria in $5000 \mathrm{~m}$ were higher than in $2000 \mathrm{~m}$ in the chicken farm. The number of resistant bacteria in 1000 meters around farms was higher than in $500 \mathrm{~m}$ in quail farm. Then, the number of resistant bacteria in 1000 meters was same as in 500m in pigeon farms.

Tab1. Test result of sulfanilamide antibiotic of E.coli in poultry farms

\begin{tabular}{ccccccccc}
\hline name & total & \multicolumn{7}{c}{ soil } \\
\cline { 3 - 9 } & & field & 100 & 200 & 500 & 1000 & 2000 & 5000 \\
\hline chicken farm & 28 & 9 & 6 & 4 & 3 & 4 & 1 & 2 \\
quail farm & 21 & 7 & 4 & 3 & 2 & 3 & 1 & 1 \\
pigeon farm & 17 & 7 & 4 & 3 & 2 & 0 & 1 & 0 \\
\hline total & 66 & 23 & 16 & 10 & 7 & 7 & 4 & 3 \\
\hline
\end{tabular}

\section{Antimicrobial drug susceptibility testing}

The minimum inhibition concentration of resistant strains was detected using the 6 kinds of antibiotic resistant. Antimicrobial drug susceptibility were determined by the disk-diffusion method on Mueller-Hinton agar plates as recommended by the Clinical Laboratory Standard Institute(penicillin, chloramphenicol, tetracycline, ciprofloxacin, gentamycin, and the concentration of rifampicin provisions for $16,32,4,4,16,16 \mathrm{mg} \mathrm{mL}^{-1}$ ). And so sulfonamides -resistant bacteria had the highest resistance to chloramphenicol, middle resistance to tolerance ability of penicillin, tetracycline, ciprofloxacin and the lowest resistance to rifamicin. The result showed in figure 1. Separation of sulfa strongest resistant bacteria tolerance ability of chloramphenicol, penicillin, tetracycline, ciprofloxacin and gentamicin tolerance, tolerance of rifampicin, the weak and the poles distribution. More than CLSI standard strains, 3 strains contains 6 kinds of antibiotic resistance, 4 strains containing 5 kinds of antibiotic resistance, 6 strains containing from 4 kinds of antibiotic resistance, 7 strains contain three kinds of antibiotic resistance, 11 strains contain two kinds of antibiotic resistance, and 13 strains containing one kind of antibiotic resistance. But different proportion of sulfonamides resistance was observed in different animal species. 


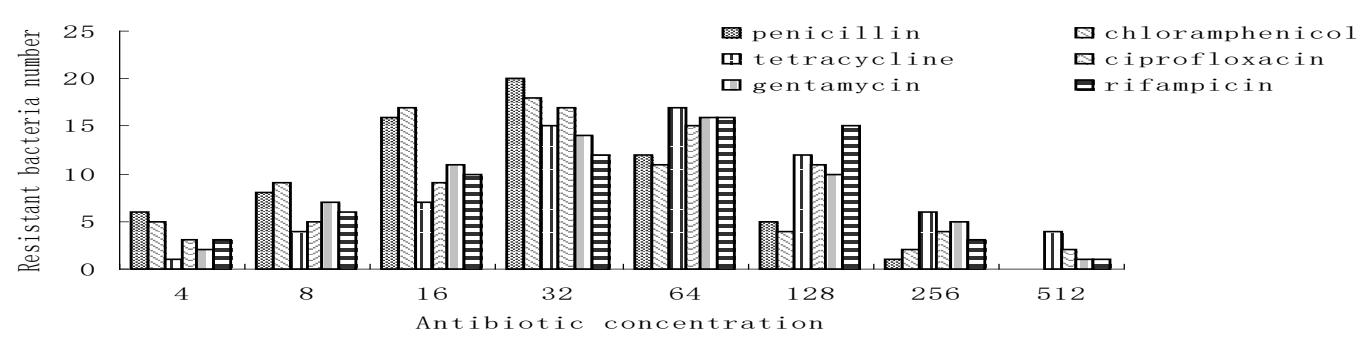

Fig1. Minimum inhibitory concentration distribution of sulfonamides resistant bacteria to 6 antibiotics in farm

\section{Analysis of resistance genes}

Sulfonamide resistance was different from isolated E. coli. 89 sulfonamides resistance genes were detected from chicken farm (40), quail farm (27) and dove farm (22), respectively. Among sul1 、sul 2、 sul 3、 int1 and int2, they were detected 34(51.2\%), 16(24.2\%), 10 (15.2 \%), 20 (30.4\%) and 9 (13.6\%), respectively. 48 strains contained only one kind of resistance genes, 6 strains contained two kinds of resistance genes and 4 strains contained three kinds of resistance genes. Only 3 strains contained four genes, 1 strain contained five genes in farm. Oddly enough, 4 strains of the resistant were not detected resistance gene, whcih1, 1 and 2 stains were not detected resistance gene in the chicken farm, quail farm and pigeon farm, respectively. The content of antibiotic residues, resistance genes and resistance bacteria were higher relatively in close to farms than in far way farms. But resistance bacteria were different with far way 200 meters from farms. The content of resistant bacteria and resistance genes in chicken farm was highest than quail and pigeon farms. Sul1 was detected in farm field, $100 \mathrm{~m}, 200 \mathrm{~m}$ around farm. Sul 2 was detected in farm field, $100 \mathrm{~m}, 200 \mathrm{~m}$ around farm, which was not detected in $1000 \mathrm{~m}, 2000 \mathrm{~m}$ and $5000 \mathrm{~m}$ around farm. Sul 3 was detected in farm field, $100 \mathrm{~m}, 200 \mathrm{~m}, 500 \mathrm{~m}$ and1000m around farm, which was not detected in $2000 \mathrm{~m}$ and $5000 \mathrm{~m}$ around farm. Int1 was detected in the farm except $5000 \mathrm{~m}$ around farm. Int 2 was detected in $2000 \mathrm{~m}$ around farm. 5 genes was in the farm field, and 4 genes was in the $100 \mathrm{~m}$ around farm, while 1 gene was in $5000 \mathrm{~m}$ around farm

Tab.2. Number and proportion of antibiotic-resistant bacteria

\begin{tabular}{|c|c|c|c|c|c|c|c|c|c|c|c|}
\hline \multirow[t]{2}{*}{ farm } & \multirow{2}{*}{$\begin{array}{c}\text { strain } \\
\text { number }\end{array}$} & \multicolumn{6}{|c|}{1 kind of resistance gene } & \multirow{2}{*}{$\begin{array}{l}2 \text { kinds } \\
\text { of genes }\end{array}$} & \multirow{2}{*}{$\begin{array}{l}3 \text { kinds of } \\
\text { genes }\end{array}$} & \multirow{2}{*}{$\begin{array}{l}4 \text { kinds } \\
\text { of genes }\end{array}$} & \multirow{2}{*}{$\begin{array}{l}5 \text { kinds } \\
\text { of genes }\end{array}$} \\
\hline & & total & sul1 & sul2 & sul3 & int 1 & int 2 & & & & \\
\hline chicken farm $^{\text {a }}$ & 28 & 40 & 18 & 6 & 4 & 8 & 4 & 2 & 2 & 1 & 1 \\
\hline quail farm ${ }^{b}$ & 21 & 27 & 9 & 6 & 3 & 6 & 3 & 2 & 1 & 1 & 0 \\
\hline pigeon farm ${ }^{c}$ & 17 & 22 & 7 & 4 & 3 & 6 & 2 & 2 & 1 & 1 & 0 \\
\hline total & 66 & 89 & 34 & 16 & 10 & 20 & 9 & 6 & 4 & 3 & 1 \\
\hline
\end{tabular}

a: 1 not detected gene; b: 1 non-sensitive strain, c: 2 not detected gene

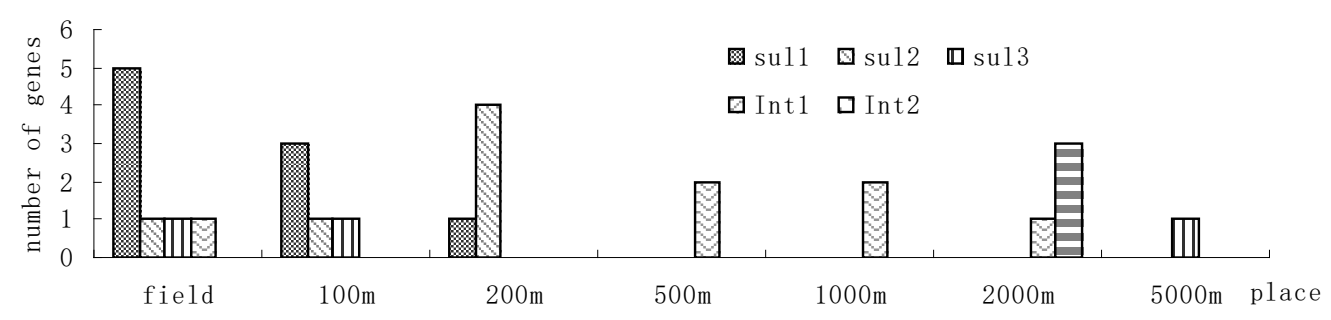

Fig.2 The number of sulfonamides resistance genes in chicken farm 


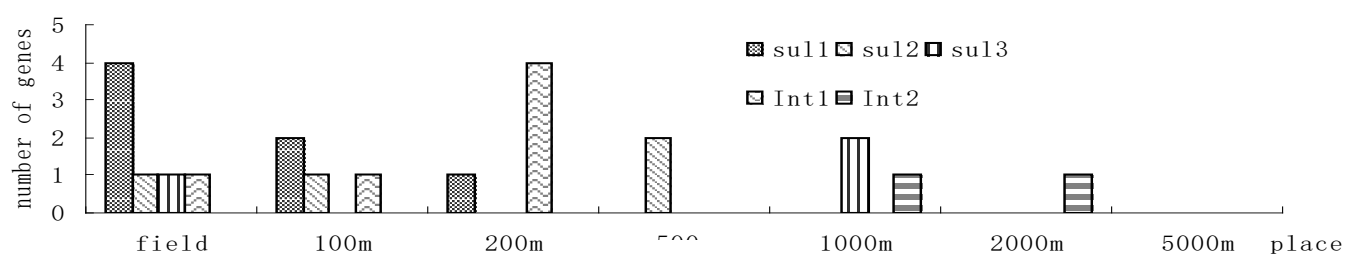

Fig.3 The number of sulfonamides resistance genes in quail farm

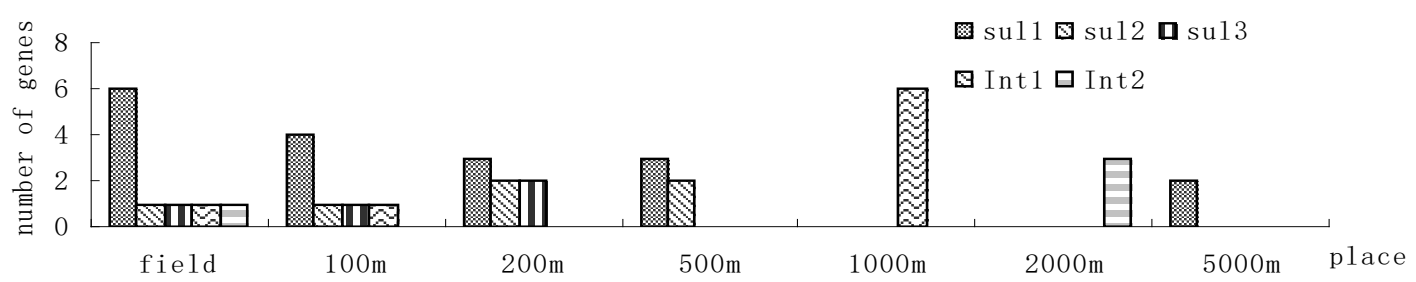

Fig.4 The number of sulfonamides resistance genes in chicken far

\section{Conclusion}

In this study, 8-13 kinds of antibiotics were used at the chickens farm, quail farm and pigeon farm through the JiLin province. The survey investigated several factors, such as breeding scale, commonly used antibiotics, antibiotic usage and dosage, geographic position around farm, and other factors. The antibiotics resistance strains isolated from chicken farm were the most sensitive, the number of resistant strains were the largest, with multiple antibiotic resistance. The same number of antibiotic resistant strains and antibiotic resistance genes were detected in $1000 \mathrm{~m}$ and $2000 \mathrm{~m}$. The phenotype of antibiotic resistant strains and expression type appear not perfectly match phenomenon, poultry farm in the antibiotic resistant bacteria, residues of the resistance gene was affected by many factors. The results of this study suggest that agricultural activities, specifically antimicrobial use may have a significant impact on antibiotic multiple resistance evolution in general. More studies with larger sample sizes and more precise antibiotic multiple resistance genes typing by DNA further throw more light in this regard. In conclusion, E. coli from poultry farms were resistant to commonly used antibiotics and was highly genetically diverse. In this setting, the sulfonamides resistance did not coincide with the presence of such genes completely

\section{Acknowledgement}

In this paper, the research was sponsored by the National Natural Science Foundation of China (Project No. 51208226) and Jilin province education department project (Project No. 20150168).

\section{References}

[1] Su J Q, Huang FY, Zhu YG. Antibiotic resistance genes in the environment. Biodiversity Science, 2013, 21(4): 481-487.

[2] Kennedy D. Time to Deal with Antibiotics. Science, 2013, 342 (160) : 777.

[3] YANG Fengxia, MAO Daqing, LUO Yi, et al. Horizontal transfer of antibiotic resistance genes in the environment. Chinese Journal of Applied Ecology, 2013, 24(10) : 2 993-3 002.

[4] Chen b W, Liang X M, Huang X P, et al. Differentiating anthropogenic impacts on ARG s in the Pearl River estuary by using suitable gene indicators. Water Research, 2013, 47:2811-2820.

[5] Clinical and laboratory standards institute (CLSI).2006a.Method for broth dilution 
susceptibility testing of bacteria isolated [S]. Wayne, PA, USA: CLSI.

[6] National Committee for Clinical Laboratory Standards. NCCLS Document M1002S12, 2002b. Performance standards for antimicrobial susceptibility testing; twelfth informational supplement[S].

[7] Zhang H J. Distribution of antibiotic resistance genes and related resistance genes in the Haihe River basin evolution analysis [D]. Shenyang: Shenyang Pharmaceutical University, 2009,40-44.

[8] Pruden A, Larsson D G, Amézquita A, et al. Management options for reducing the release of antibiotics and antibiotic resistance genes to the environment. Environ Health Perspect, 2013, 121(8): 878-885.

[9] Lopes G V, Pissetti C, da Cruz Payão Pellegrini D, et al. Resistance Phenotypes and Genotypes of Salmonella enterica subsp. enterica Isolates from Feed, Pigs, and Carcasses in Brazil. J Food Prot, 2015, 78(2):407-413.

[10]Gao P, Mao D Q, Luo Y, et al. Occurrence of sulfonamide and tetracycline resistant bacteria and resistance genes in aquaculture environment. Water Research, 2012, 46:2355-2364.

[11]Lucia Birošová, Tomáš Mackul'ak, Igor Bodík, et al. Pilot study of seasonal occurrence and distribution of antibiotics and drug resistant bacteria in wastewater treatment plants in Slovakia. Science of The Total Environment, 2014, 490:440-444.

[12]Qi S Y, Ren S W, Li X L, et al. Multidrug-resistant bacteria in livestock feces. Acta Ecologica Sinica, 2013, 33(13):3 970-3 977.

[13]Flórez AB, Campedelli I, Delgado S, et al. Antibiotic Susceptibility Profiles of Dairy Leuconostoc, Analysis of the Genetic Basis of Atypical Resistances and Transfer of Genes In Vitro and in a Food Matrix. PLoS ONE, 2016,11(1): e0145203. 